\title{
SELECTED SUMMARY
}

\section{Medical malpractice}

\section{BASHIR MAMDANI}

811, N. Oak Park Avenue, Oak Park, Illinois 60302, USA. e-mail: bmamdani@ comcast.net

Studdert DM, Mello MM, Brennan TA. Medical malpractice. $N$ Engl J Med 2004;350:283-92

This article examines available evidence on the efficacy of the US medical malpractice system to promote safer medicine and adequately compensate patients wrongfully injured.

\section{Framework and goals of the system}

The social goals of malpractice litigation include deterrence against unsafe practices, compensation for injury through negligence, and exact corrective justice. The attorney acts as the gatekeeper by evaluating the prospective plaintiff's story, gauging the costs of bringing the lawsuit, and estimates the probability of success and the likely award. The functioning of the malpractice system is efficient in theory; the actual practice is more complicated.

\section{Empirical research on the malpractice system}

Studies from different parts of the US showed identical rates of iatrogenic injury ( $4 \%-5 \%$ of admissions) and malpractice claims (10\%). While only $2 \%$ of negligent injuries resulted in malpractice claims, only $17 \%$ of malpractice claims involved negligence. The key predictor of payment was the plaintiff's degree of disability. The data reveal a profoundly inaccurate and inefficient mechanism for distributing compensation. Sixty per cent of compen-sation is absorbed by administrative costs (predominantly legal fees).

The malpractice system's role in improving care is less well studied. Tort law encourages ordering of tests and procedures of little medical benefit, primarily for the purpose of reducing medicolegal risk. A new malpractice insurance crisis has evolved over the past few years in the shadow of a patient-safety movement precipitated by The Institute of Medicine's 2000 report on medical errors. The interconnectedness of patient safety and malpractice is increasingly apparent.

\section{Malpractice law and patient safety}

There is a deep-seated tension between the malpractice system and goals of the patient-safety movement. The problem is one of conflicting cultures: trial attorneys believe that the threat of litigation makes doctors practise more safely, but the punitive, individualistic, adversarial approach of tort law is antithetical to the non-punitive, systems-oriented, cooperative strategies of the patientsafety movement.

Transparency has become the leitmotif of the patient-safety movement: to learn from errors, we must first identify them; to identify them, we must foster an atmosphere that is conducive to openness about mistakes. Hospitals and physicians must be honest with patients about medical errors, report such events to one another and to regulators, and address methods of prevention. To nurture openness, experts stress that most errors arise from the faulty systems, not from clinicians' incompetence or carelessness. In sharp contrast, tort law targets individual physicians, assigning blame and demanding compensation on the basis of proof of negligence. Concern about exposure to malpractice litigation diminishes the interest of the medical profession in patient-safety activities, as doctors feel that they are being asked to be open about errors with little or no assurance of legal protection.

\section{Tort reform}

Conventional tort reforms can be divided into:

A. Limiting access to court. Screening panels evaluate the merits of claims before they reach court.

B. Change liability rules to reduce the size of payouts.

C. Caps on damages awards and attorneys' fees.

Critics of malpractice litigation point out that it is unrealistic to expect that increased levels of malpractice litigation will promote patient safety or make compensation for injuries more accurate or fair. Also, insurance premiums are dictated as much by losses that insurance companies suffer as by the size of the payouts and therefore tort reform may not prevent premium crises.

\section{Reform of the system}

Over the past 20 years, a growing sense that the tort system is flawed has led to a number of alternatives. The leading recommendations include using alternative mechanisms to resolve disputes, dispensing with negligence as the basis for compensation (no-fault) and locating responsibility for accidents at the institutional level (enterprise liability). Most likely, this will result in another round of 
conventional tort reforms, which will do little to alleviate the haphazardness of compensation. Proponents of patient safety will continue to wrestle with an adversarial litigation system that undermines the goals of transparency and error reduction.

\section{Commentary}

In 1992, the Kerala High Court extended the 1986 Consumer Protection Act to medical malpractice and negligence. While activists and consumer protection groups welcomed this, most physicians were unanimous in their opposition and promptly took this to the Supreme Court (1). The Kerala High Court's opinion was upheld by the Supreme Court. Rules were drawn up and appropriate courts established in all states to handle consumer complaints. While the lay press has published many accounts of its aftermath, mainstream medical journals have been surprisingly silent. In contrast, several articles have appeared in the pages of this Journal (2-5).

Almost a decade after the High Court ruling, panelists at an annual Tamil Nadu Orthopaedic Association meeting (3) expressed that the Act was needed as unethical practices had become common in the medical profession and the Act had forced an improvement in the equipment of nursing homes. The lawyers on the panel thought that the present Act needed fine-tuning.

In terms of error reporting, a study examined physician attitudes towards revealing iatrogenic errors to patients. Doctors at the Apollo Hospitals in New Delhi and at the University of Chicago Hospital in Chicago were asked to complete a questionnaire (4), which presented three scenarios: A 75-year-old, terminally ill patient suffers a cardiac arrest; a 75-year-old, terminally ill patient suffers a cardiac arrest from an unknown allergy to an antibiotic; and a 75-year-old, terminally ill patient suffers a cardiac arrest as a result of a known but forgotten allergy to a prescribed antibiotic. In each case, the physician is asked whether or not he/she would resuscitate the patient. Who is informed when a mistake is made? Are there any legal issues that are of concern when revealing iatrogenic error? Was any training received in medical school on how to handle mistakes?

In Delhi, 55\% would resuscitate the patient in scenario 1. This increased to $87.5 \%$ for scenario 2 and $95 \%$ for scenario 3. The corresponding figures for the US were $50 \%, 82.5 \%$ and $82.5 \%$. In both countries, almost all the doctors felt a sense of moral duty to resuscitate iatrogenic cardiac arrest. In Delhi, 57.5\% could not identify a hospital department they could report the error to, while in Chicago $87 \%$ would report it to the risk management rather than quality assurance department. Seventy-five per cent of the Indian and $90 \%$ of the US physicians would report the error to the patient, and $72.5 \%$ to the patient's family also. The most common reason for this was the sense of duty to be honest with the patient and family. Ninety per cent of the doctors in both countries were concerned about the legal ramifications. Sixty-five per cent of the Indian doctors and $50 \%$ of the US physicians said they had not received any instruction during their training on how to handle mistakes. The similarity between the physicians' responses in the two countries is striking. Despite differences in the cultural and health care settings, physicians in both countries felt a moral duty to resuscitate a patient who had suffered an iatrogenic injury.

The malpractice systems in India and the US differ mainly in that in the US such cases are handled by state courts. Guilt and retribution are determined by a jury. Faced with the stark contrast of a 'poor' disabled patient against a 'rich' insurance company and doctor, juries often favour the patient and large awards for pain and suffering are not unusual. In India, special consumer courts handle the cases. Awards are restricted to actual damages. Thus, the kind of malpractice insurance crises seen in the US are not likely here. In addition, lawyers are not permitted to take cases on contingency basis. In India, doctors continue to have an exalted status, with few patients, even wealthy ones, questioning their decisions, though this may be changing.

However, neither system has the capacity to fairly and accurately identify all errors and injuries that result. In the US, there is a fledgling patient-safety movement to reduce the rate of iatrogenic errors with a legal requirement for doctors and hospitals to report all errors. At present, there is no move to link this with a compensation scheme, although many approaches have been proposed. Dr Sunil Pandya (5) described the New Zealand practice of establishing a fund to compensate patients who suffer an injury, whether from negligence or malpractice. It is time doctors in India take the initiative and develop similar proposals to self-monitor and report errors not only to reduce the rate of inappropriate care and negligent injuries but also to establish fair guidelines for compensation of those injured.

\section{References}

1. Nagral S. The Consumer Protection Act. J Postgrad Med 1992;38:214-5.

2. Pilgaokar, A. Doctors and the Consumer Protection Act [Editorial]. Issues in Medical Ethics 1996;4:2.

3. Thomas G. Consummate justice or complete folly? Doctors and Consumer Protection Act. Issues in Medical Ethics 2002;10:28.

4. Maithel SK. Iatrogenic error and truth telling: a comparison of the United States and India. Issues in Medical Ethics 1998;6:125-7.

5. Pandya SK. Compensation by State: eliminating legislation against doctors. Issues in Medical Ethics 1993;1:4. 